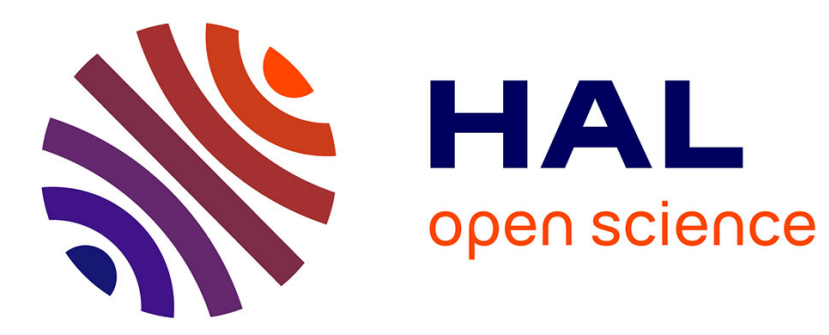

\title{
Microstructure and residual stresses in Ti-6Al-4V alloy pulsed and unpulsed TIG welds
}

B Mehdi, Riad Badji, V Ji, B Allili, D Bradai, Frédéric Deschaux-Beaume, Fabien Soulié

\section{- To cite this version:}

B Mehdi, Riad Badji, V Ji, B Allili, D Bradai, et al.. Microstructure and residual stresses in Ti6Al-4V alloy pulsed and unpulsed TIG welds. Journal of Materials Processing Technology, 2016, 231, pp.441-448. 10.1016/j.jmatprotec.2016.01.018 . hal-01289332

\section{HAL Id: hal-01289332 \\ https://hal.science/hal-01289332}

Submitted on 16 Mar 2016

HAL is a multi-disciplinary open access archive for the deposit and dissemination of scientific research documents, whether they are published or not. The documents may come from teaching and research institutions in France or abroad, or from public or private research centers.
L'archive ouverte pluridisciplinaire HAL, est destinée au dépôt et à la diffusion de documents scientifiques de niveau recherche, publiés ou non, émanant des établissements d'enseignement et de recherche français ou étrangers, des laboratoires publics ou privés. 


\title{
Microstructure and residual stresses in Ti-6Al-4V alloy pulsed and unpulsed TIG welds
}

\author{
B. Mehdi ${ }^{\text {a,b,c }}$, R. Badji ${ }^{\mathrm{a}, *}$, V. Ji ${ }^{\mathrm{b}}$, B. Allili ${ }^{\mathrm{c}}$, D. Bradai ${ }^{\mathrm{c}}$, F. Deschaux-Beaume ${ }^{\mathrm{d}}$, F. Soulié $^{\mathrm{d}}$ \\ ${ }^{a}$ Research Centre in Industrial Technologies CRTI, P. O. Box 64, Cheraga, Algeria \\ ${ }^{\mathrm{b}}$ ICMMO/SP2M, Université-Paris-Sud 11, bat 410, Orsay Cedex, France \\ c Faculté de Physique, USTHB, BP 32 El-Alia, Algiers, Algeria \\ ${ }^{\mathrm{d}}$ Laboratoire de Mécanique et Génie Civil (LMGC), Université de Montpellier, CNRS, Montpellier, France
}

\begin{abstract}
A B S T R A C T
Increasing the pulse frequency in pulsed Tungsten Inert Gas arc welding refines the prior- $\beta$ grain size in the fusion zone of Ti-6Al-4V alloy compared to unpulsed process. The microhardness increases in the fusion zones (FZs) obtained with pulsed welding process with respect to their microstructural evolution. The increase of the pulse frequency contributes to the formation of a significant amount of residual $\beta$ phase in the FZ which is accompanied by a decrease of its microhardness. The tensile residual stresses (RSs) level in the pulsed process is lower than the one of the unpulsed one. The tensile RSs induced by both welding processes in the heat affected zone (HAZ) are found to decrease when increasing the pulse frequency. In the FZ, the transversal RSs are of compressive type for both processes whereas the longitudinal ones change from tensile to compressive type when increasing the pulse frequency.
\end{abstract}

Keywords:

Ti-6Al-4V alloy

Welding

Pulsed current

Microstructure

Residual stress

\section{Introduction}

For many applications of the $(\alpha+\beta)$ Ti-6Al-4V alloy, Tungsten Inert Gas welding (TIG) is commonly used as an assembling process. During fusion welding, the Ti-6Al-4V Base Metal (BM) is subjected to a typical thermal cycle that causes complex microstructural transformations. Sundaresan et al.(1999) indicated that the microstructure of the HAZ undergoes both rapid heating and cooling that cause significant growth of the prior- $\beta$ grains. Chen and Devletian (1990) observed a lamellar $(\alpha+\beta)$ structure within coarse prior- $\beta$ grains in the HAZ of Ti-6Al-4V fusion welds. Some retained equiaxed prior $\beta$ grains can also be observed in this region as reported by Pasang et al. (2013). The microstructure of the FZ results from the combination of solidification and solid state transformation processes. Sundaresan et al. (1999) reported that the FZ microstructure of Ti-6Al-4V alloy consists of coarse prior- $\beta$ grains and acicular $\alpha$ and $\alpha$ phases. According to Balasubramanian et al. (2008a), the formation of such microstructures is due to the prevailing thermal effect that occurs during the weld metal solidification and cooling. Kishore and Ganesh (2006) pointed out that in the case of high cooling rates, the $\beta$ phase transforms to $\alpha$

\footnotetext{
* Corresponding author. Fax: +213 21342019.

E-mail addresses: riadbadji@gmail.com, riadbadji1@yahoo.fr (R. Badji).
}

martensite through a displacive mechanism. This was supported by $\mathrm{Oh}$ et al. (2003) who compared microstructures obtained in the FZ of TIG and Electron Beam (EB) welds. The very high cooling rate induced by the EB process has caused the formation of $\alpha$ phase, whereas only the $\alpha$ phase is formed in the FZ obtained with TIG process as a result of a lower cooling rate. Recently, a coupled thermal and metallurgical model has been proposed by Gaoyang et al. (2014) to study on the one hand, the kinetics of the $\alpha+\beta \rightarrow \beta$ transformation during heating and on the other hand, the $\beta \rightarrow \alpha$ transformation during cooling. Then, welding thermal histories and the volume fraction of the retained- $\beta$ phase during the TIG welding of the Ti- $6 \mathrm{Al}-4 \mathrm{~V}$ alloy have been determined. Consequently, a loss of mechanical properties (namely the ductility) was often recorded in Ti-6Al-4V TIG welds due to their coarse grained microstructure. In practice, several approaches are adopted to refine the prior- $\beta$ grains in the FZ and HAZ of the Ti-6Al-4V TIG welds. Among these approaches, pulsed current TIG welding permits to refine the grain size, reduce the width of the HAZ and control the chemical segregations. The beneficial effect of the current pulsing on the microstructure and properties of Ti-6Al-4V welds has been reported by several authors. Kishore et al. (2007) published that the current pulsing results in higher hardness,tensile strength and excellent ductility. Sundaresan et al. (1999), Yang et al. (2015) and Balasubramanian et al. (2008b) observed a grain refinement 
Table 1

Chemical composition of as received Ti-6Al-4V sheets.

\begin{tabular}{|c|c|c|c|c|c|c|c|}
\hline Elément & $\mathrm{Ti}$ & $\mathrm{Al}$ & V & $\mathrm{O}$ & C & $\mathrm{N}$ & $\mathrm{Fe}$ \\
\hline$\%$ en poids & Balance & 6.24 & 3.83 & 0.18 & 0.01 & 0.01 & 0.20 \\
\hline
\end{tabular}

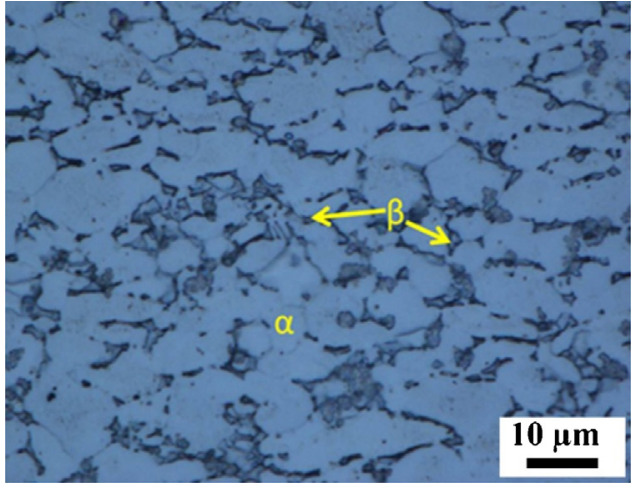

Fig. 1. Optical micrograph of the as received base metal.

in the FZ and an appreciable increase in ductility of Ti-6Al-4V TIG welds due to current pulsing.

Residual stresses generated during welding generally have a detrimental effect on the mechanical behavior of structural parts, and can induce distortions. Welding RSs in titanium alloys are the result of the high thermal gradients and the associated microstructural changes produced by this process. However, RSs distribution is very difficult to predict because of the complex coupling between thermal, metallurgical and mechanical phenomena. Zhang et al. (2005) found a similar distribution of the RSs in the Ti-6Al-4V laser beam and TIG welds. They stated that the maximal RSs in the HAZ of laser beam welds were about $100 \mathrm{MPa}$ lower than those of TIG welds. They also concluded that post weld heat treatment under vacuum can relieve about $90 \%$ of the RSs for both laser beam and TIG welding processes. Similar RSs evolution was found by Sprauel et al. (1980). They have determined RSs distribution in both TIG and electron beam welding of Ti-6Al-4V welds and pointed out that these RSs were of compressive type in the HAZ and of tensile type in the FZ.

Despite the numerous papers that deal with the microstructure and the mechanical behavior in fusion welds of titanium alloys, information concerning the effect of pulsed TIG process on microstructure and RS evolution in the Ti-6Al-4V alloy needs to be more detailed. Therefore, this work focuses on the effect of pulsed and unpulsed TIG welding processes on microstructure and residual stresses in Ti-6Al-4V welds. The RSs distributions are discussed and related to the microstructural evolution for the different welding cases.

\section{Material and experimental procedure}

Commercial Ti-6Al-4V, provided as hot rolled and annealed sheets of $2 \mathrm{~mm}$ thickness with the chemical composition presented in Table 1, was used in this work.

TIG arc welding with pulsed and unpulsed currents under pure argon shielding gas was used as a joining process. The main welding parameters used in this work are listed in Table 2.

Metallographic samples crossing the different welding zones (i.e., BM, HAZ and FZ) were prepared for optical microscopy examination using standard mechanical polishing. The polished cross-sections were etched in a solution containing $85 \% \mathrm{H}_{2} \mathrm{O}+10 \%$ $\mathrm{HNO}_{3}+5 \% \mathrm{HF}$ and analyzed using a Nikon Eclipse LV $100 \mathrm{ND}$ optical microscope equipped with a digital camera. The grain size was
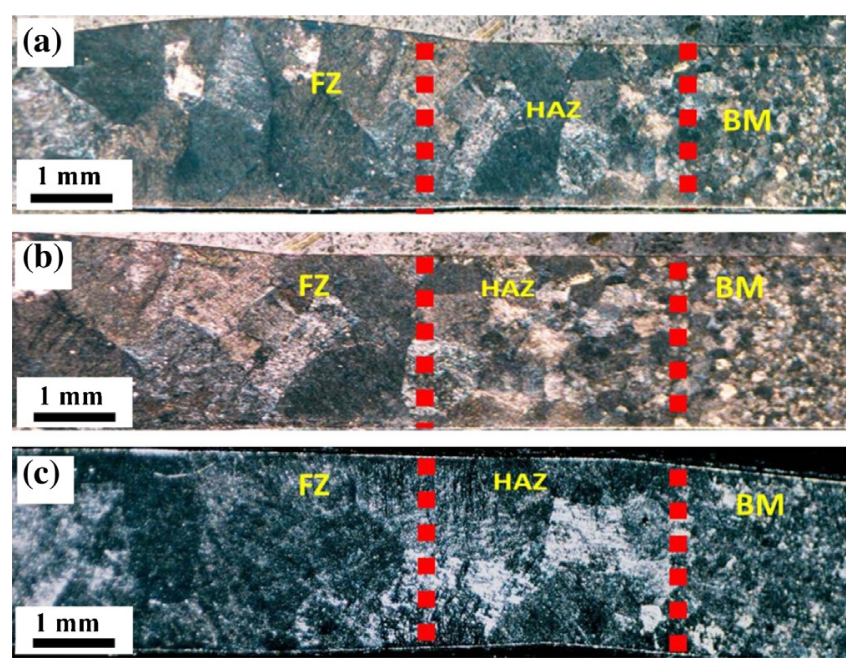

Fig. 2. Optical macrographs obtained from the different welding conditions (a) unpulsed process, (b) $1 \mathrm{HZ}$ pulse frequency, (c) $5 \mathrm{HZ}$ pulse frequency.

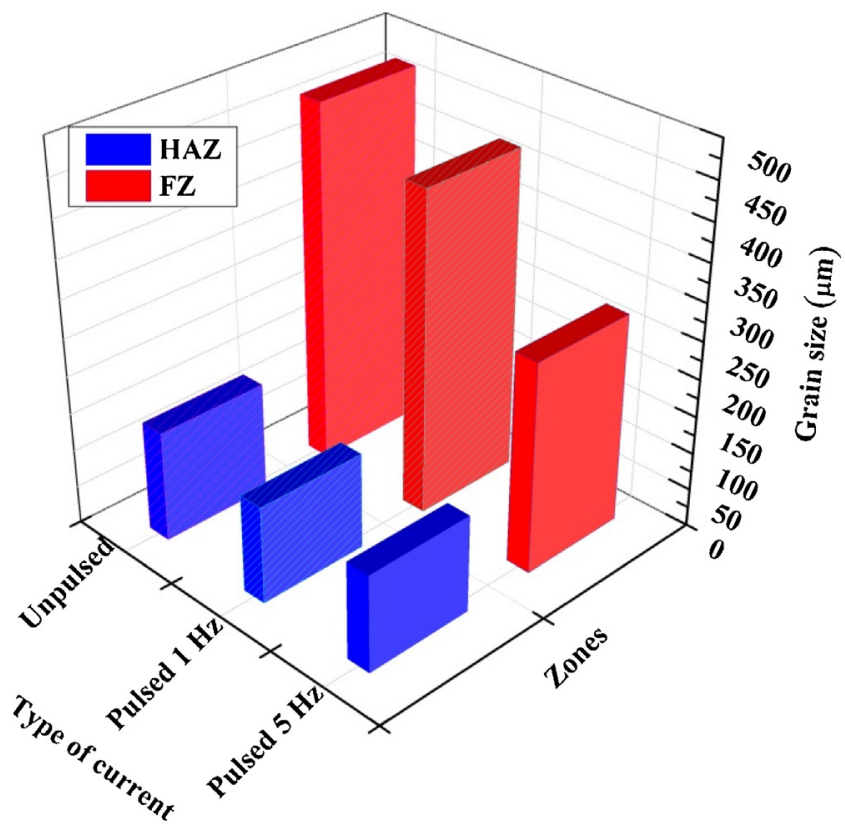

Fig. 3. Evolution of prior- $\beta$ grain size in the $F Z$ and $H A Z$ for the different welding conditions.

Table 2

Welding parameters.

\begin{tabular}{ll}
\hline Electrode diameter & $2.4 \mathrm{~mm}$ \\
\hline Sharpening angle & 30 \\
Argon gas flow & $11 \mathrm{l} / \mathrm{min}$ \\
Pulsed current frequency & $1,5 \mathrm{~Hz}$ \\
Arc height & $2.7 \mathrm{~mm}$ \\
Pulse time/background time & $50 / 50$ \\
Pulse current & $50 \mathrm{~A}$ \\
Background current & $100 \mathrm{~A}$ \\
Constant unpulsed current & $80 \mathrm{~A}$ \\
Welding speed (pulsed an unpulsed) & $10 \mathrm{~cm} / \mathrm{min}$ \\
Voltage (pulsed an unpulsed) & $10 \mathrm{~V}$
\end{tabular}



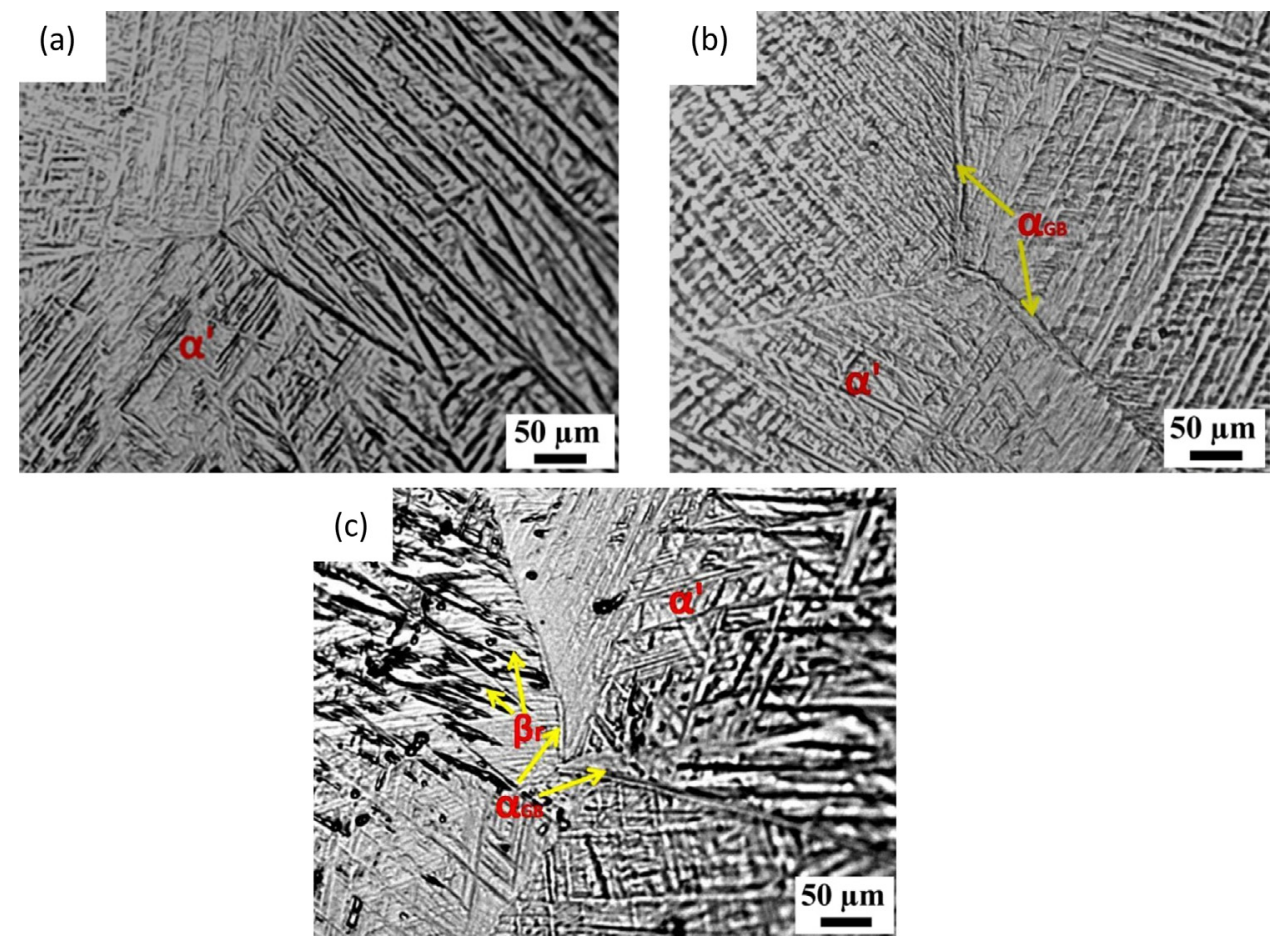

Fig. 4. Optical micrographs of the fusion zone (a) unpulsed process (b) $1 \mathrm{HZ}$ pulse frequency (c) $5 \mathrm{HZ}$ pulse frequency.
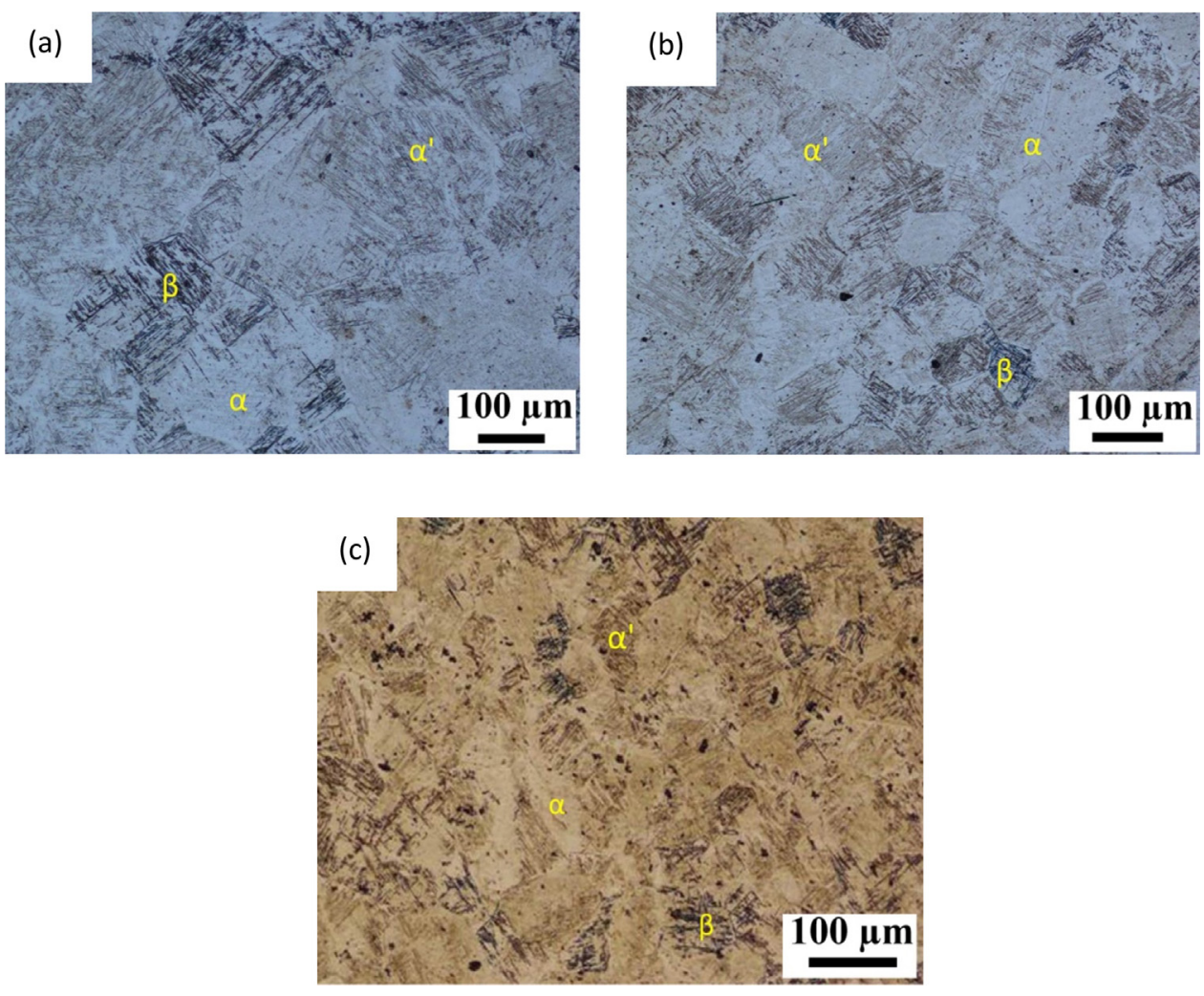

Fig. 5. Optical micrographs of the heat affected zone (a) unpulsed process, (b) $1 \mathrm{HZ}$ pulse frequency (c) $5 \mathrm{HZ}$ pulse frequency.

measured by means of an automatic ATLAS image analysis system. An X-Pert-Pro Panalytical X-ray diffractometer operating at $40 \mathrm{kV}, 40 \mathrm{~mA}$ with CuK $\alpha$ radiation $(\lambda=1.54 \AA)$ was used to identify the present phases in the weld joint. The diffraction patterns are obtained by varying $2 \theta$ from $30^{\circ}$ to $80^{\circ}$ with a scan step of $0.02^{\circ}$. Microhardness measurement was done by a Vickers SHI-
MADZU type HMV-2 microhardness tester using a load of $300 \mathrm{~g}$ for $10 \mathrm{~s}$ loading time. Each presented value is an average of 5 measurements. Residual stresses measurement was done by X-ray technique using the $\sin ^{2} \psi$ method (Noyan and Cohen (1987) following the methodology given in the European and standard (2009) on Set-X instrument with $\mathrm{Cu}-\mathrm{K} \alpha$ radiation operating at $20 \mathrm{KV}$ and 

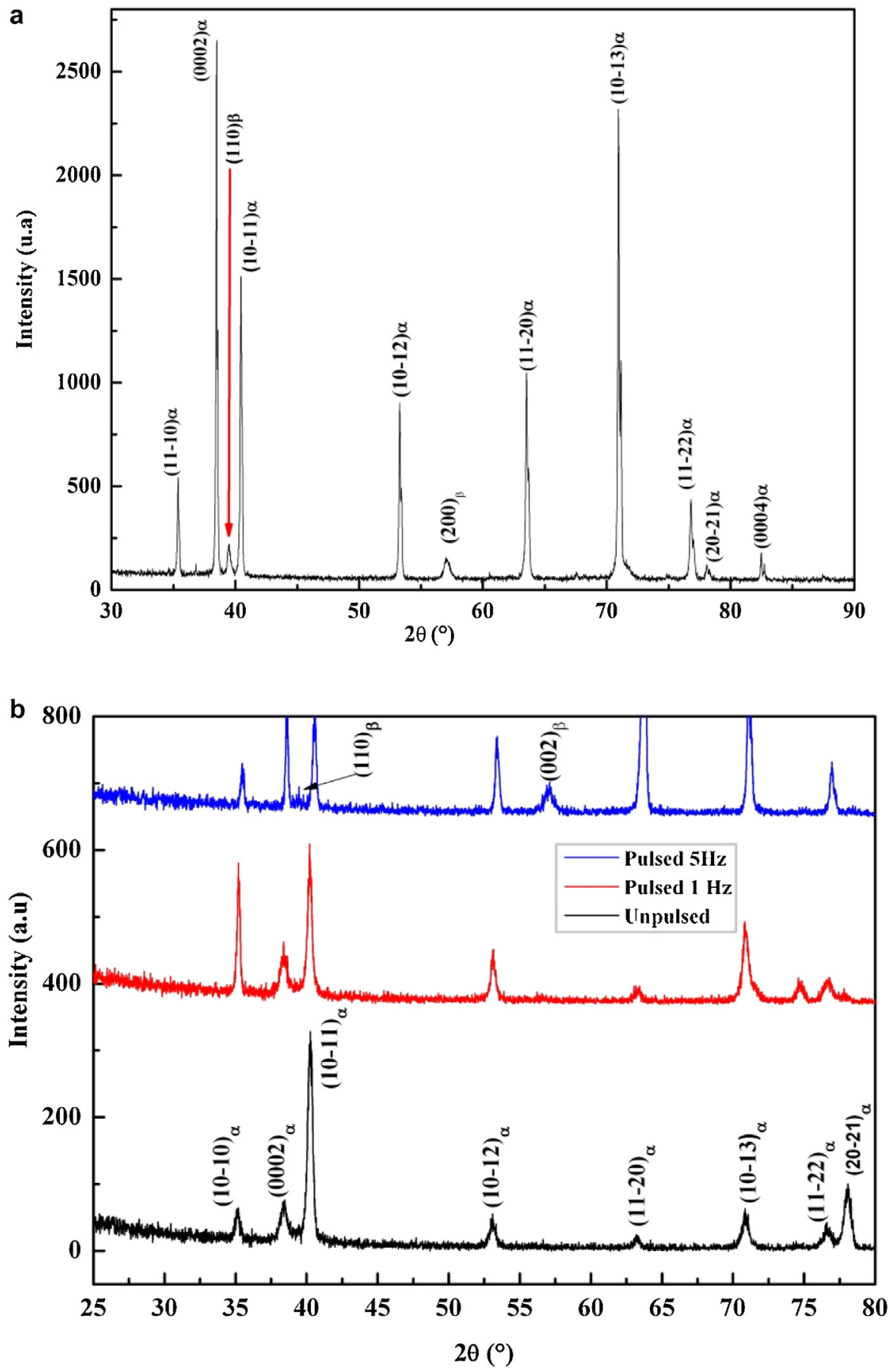

Fig. 6. X-ray spectrums of (a) base metal (b) fusion zones.

$5 \mathrm{~mA}$. After the calibration of the equipment by means of a standard Ti-6Al-4V specimen, $13 \psi$ angles (comprised between $-37^{\circ}$ and $+37^{\circ}$ ) were used for stress analysis. The deformation $\varepsilon \phi \psi$ measurements were made on the $\{21-33\}$ atomic plane situated at $2 \theta=142^{\circ}$. It should be noted that, the RSs can be calculated with the use of elastic constants of the studied material: Young modulus ( $E=120 \mathrm{GPa})$, Poisson coefficient $(v=0.3)$ and the anisotropic factor $\left(A_{\mathrm{RX}}=1\right)$. The accuracy of the RSs analysis in this work was about $\pm 50 \mathrm{MPa}$. The longitudinal RSs were analyzed in a parallel direction to the fusion line (that is parallel to the rolling direction of the sheet) whereas the transversal ones were analyzed perpendicularly to the fusion line (that is parallel to the transverse direction of the sheet). It is worth mentioning that, the analyzed depth by XRD for stress determination was about $15 \mu \mathrm{m}$.

\section{Results}

\subsection{Effect of welding process on microstructure evolution}

Fig. 1 is an optical micrograph of the as received base metal that shows the presence of both $\alpha$ and $\beta$ phases. The $\alpha$ phase, with an average grain size of about $15 \mu \mathrm{m}$, dominates the microstructure. Fig. 2(a-c) contains optical macrographs that reveal the different regions of the weld joint (BM, HAZ, FZ). The evolution of the grain size of the prior- $\beta$ phase in the HAZ and the FZ is represented in 


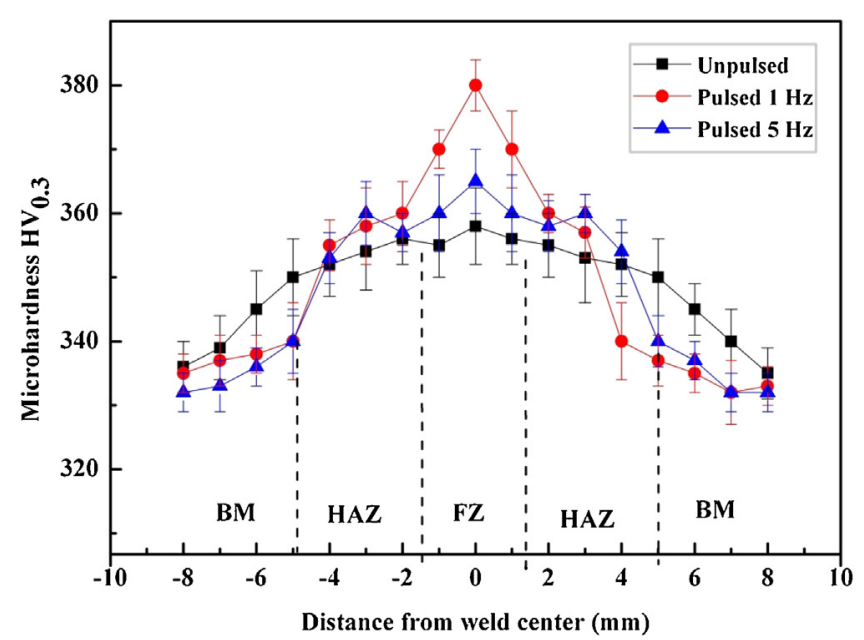

Fig. 7. Microhardness distribution across the weld joint for the different welding conditions. The distribution of the longitudinal RSs across the weld joint is given in Fig. 8a. While compressive stresses in the range of $-450 \mathrm{MPa}$ to $-250 \mathrm{MPa}$ were found in the BM, tensile ones were recorded near the fusion line after the welding process.

Fig. 3. The unpulsed process produced very large prior- $\beta$ grains in the FZ with an average size of $470 \mu \mathrm{m}$ (Fig. 2a). In fact, the unpulsed process induces significant grain growth in the HAZ where the average prior- $\beta$ grain size is about $150 \mu \mathrm{m}$. The use of the pulsed process caused some prior- $\beta$ grain refinement in the FZ which becomes more significant with the increase of the pulse frequency (Figs. $2 \mathrm{~b}$ and $c)$. Indeed, the average of prior- $\beta$ grain size decreases from $450 \mu \mathrm{m}$ to $300 \mu \mathrm{m}$ when the pulse frequency increases from $1 \mathrm{HZ}$ to $5 \mathrm{HZ}$. It should be noticed that a slight prior- $\beta$ grain refining is also observed in the HAZ due to current pulsing. In this region, the average prior- $\beta$ grain sizes that are corresponding to $1 \mathrm{HZ}$ and $5 \mathrm{HZ}$ are of $129 \mu \mathrm{m}$ and $127 \mu \mathrm{m}$, respectively.

Fig. 4(a-c) that shows optical micrographs of the FZ for the different welding conditions, illustrates the dominance of acicular morphologies within the microstructure that seem to be mainly $\alpha$ martensite as reported by Gil et al. (2001) and Ahmed and Rack (1998). However, the formation of an acicular $\alpha$ phase, that has a similar morphology to $\alpha$ phase as explained by Sundaresan et al. (1999), is not excluded. Some thin layers of diffusional $\alpha$ grain boundary and retained $\beta$ phases (named $\alpha_{\mathrm{GB}}$ and $\beta_{\mathrm{r}}$ respectively) are also observed.

For the unpulsed process (Fig. 4a), $\alpha$ appears in the form of thin needles within the prior $\beta$ grains. Acicular morphologies of this phase were also observed in the microstructure. As far as the pulsed process is concerned (Fig. $4 \mathrm{~b}, \mathrm{c}$ ), $\alpha$ martensite appears in the form of small plates within the prior- $\beta$ grains. It is noted that $\alpha_{\mathrm{GB}}$ and $\beta_{\mathrm{r}}$ are not easily distinguished from the rest of the microstructure in the case of the unpulsed process (Fig. 4a) compared to the pulsed one where $\alpha_{\mathrm{GB}}$ and $\beta_{\mathrm{r}}$ are clearly observed for the pulse frequency of $5 \mathrm{HZ}$. The microstructure of the HAZ is shown in Fig. $5(\mathrm{a}-\mathrm{c})$ and comprises both $\alpha+\beta$ structures and an acicular phase that seems to be $\alpha$.

X-ray spectrums represented in Fig. 6(a-b) confirm the aforementioned microstructural evolution. The peaks of the $\alpha$ phase dominate the spectrum of the BM where weak peak intensities of $\beta$ phase were observed (Fig. 6a). In the FZ, the X-ray spectrum shows only diffraction peaks of $\alpha$ phase for the unpulsed process. Due to the very near lattice parameters of $\alpha$ and $\alpha$ phases, these peaks correspond most probably to the dominant $\alpha$ phase observed on the micrographs. Small $\left\{\begin{array}{lll}0 & 0 & 2\end{array}\right\}$ and $\left\{\begin{array}{lll}1 & 1 & 0\end{array}\right\} \beta_{\text {r }}$ peaks are also observed in the FZs obtained in pulsed process with intensities that increase proportionally with the pulse frequency from 1 to $5 \mathrm{HZ}$ (Fig. 6b).
This indicates that the increase of the pulse frequency from 1 to $5 \mathrm{HZ}$ increases the proportion of the $\beta_{\mathrm{r}}$ phase in the FZ.

\subsection{Effect of welding process on mechanical properties}

The microhardness evolution across the weld joint for the different welding conditions is represented in Fig. 7. For the different welding cases, the microhardness decreases from the weld center toward the BM with a similar tendency. This evolution is due to the presence of $\alpha$ martensite in the FZ and HAZ, which exhibits higher hardness than the initial $\alpha+\beta$ structure as reported by Gil et al. (2001). Kishore et al. (2007) attributed this elevated hardness to the high defect density and the fine size of the martensite plates. The high hardness of the welds can be also explained by possible oxygen enrichment in the FZ and HAZ that is known for its hardening effect on titanium alloys, as discussed by Jia et al. (2015). The microhardness value of the FZ increases from $355 \mathrm{HV}$ in the unpulsed process, to $380 \mathrm{HV}$ in the pulsed process with $1 \mathrm{HZ}$. This result is probably due to the refinement in grain size of prior- $\beta$. Conversely, the increase in pulse frequency from 1 to $5 \mathrm{HZ}$ decreases the microhardness of the FZ from 380 to $365 \mathrm{HV}$ while its prior- $\beta$ grains become finer. This can be correlated to the presence of a high amount of residual $\beta$ phase in the FZ that was obtained with $5 \mathrm{HZ}$ pulse frequency and proved by the X-ray spectrum (Fig. 6), which counterbalances the grain size effect. As explained by Wang and $\mathrm{Wu}$ (2012), the hardness of $\beta$ phase is lower than that of $\alpha$ and $\alpha$ phases. This is confirmed by Kishore et al. (2007) who pointed out that the hardness reduction in After the calibration of the equipment by means of a standa TIG welds is related to the presence of diffusional $(\alpha, \beta)$ phases and the reduction in defect density. Balachandar et al. (2009) explained that the TIG pulsed current technique has several advantages, namely its compositional homogeneity. Moreover, they pointed out that the thermal effect of this process depends on the welding conditions. In the present study, when using a $5 \mathrm{~Hz}$ pulse frequency, more thermal effect was added.

The HAZ is characterized by the presence of longitudinal tensile RSs which decrease from $+250 \mathrm{MPa}$ to $+40 \mathrm{MPa}$ when increasing the pulse frequency from 1 to $5 \mathrm{HZ}$. It was likewise observed that the longitudinal RSs obtained for the pulsed process are always lower than those obtained for the unpulsed one. The longitudinal RSs induced in the FZ by the pulsed process changed from tensile to compressive type $(+103 \mathrm{MPa}$ to $-85 \mathrm{MPa})$ when the pulse frequency increased from 1 to $5 \mathrm{HZ}$. The longitudinal RSs induced by the unpulsed process in the FZ were of tensile type (Fig. 8a); their magnitude was close to that of the RSs found in the HAZ. It is important to notice that for all the welded sheets, the tensile RSs are obtained in the close regions to the fusion line.

Fig. 8b displays the transversal RSs obtained for the different welding cases. Remarkable tensile transversal RSs (+235 MPa) produced by the unpulsed process were found in the HAZ. Tensile transversal RSs with low magnitude $(+10 \mathrm{MPa}$ to $+75 \mathrm{MPa})$ are induced in the HAZ by the pulsed process of $5 \mathrm{HZ}$. The unpulsed process produces compressive transversal RSs with an average magnitude of $-50 \mathrm{MPa}$ in the $\mathrm{FZ}$. The pulsed process produces as well compressive transversal stresses but with a magnitude that varies from $(-150 \mathrm{MPa}$ to $-200 \mathrm{MPa})$ when the pulse frequency increases from 1 to $5 \mathrm{HZ}$.

Casavola et al. (2012) provided more details on the distribution of the longitudinal and transversal RSs in Ti-6Al-4V fusion welds. They noticed that the longitudinal RSs were higher than the transversal ones and mentioned that the welding process generates, in the longitudinal direction, a peak tensile stress in the centerline of the weld bead and a peak compressive stress in the lateral zones. The transversal RSs are generally of tensile type in the FZ and HAZ except in transversal cross sections near the beginning and the end of the fusion line where compressive stresses 

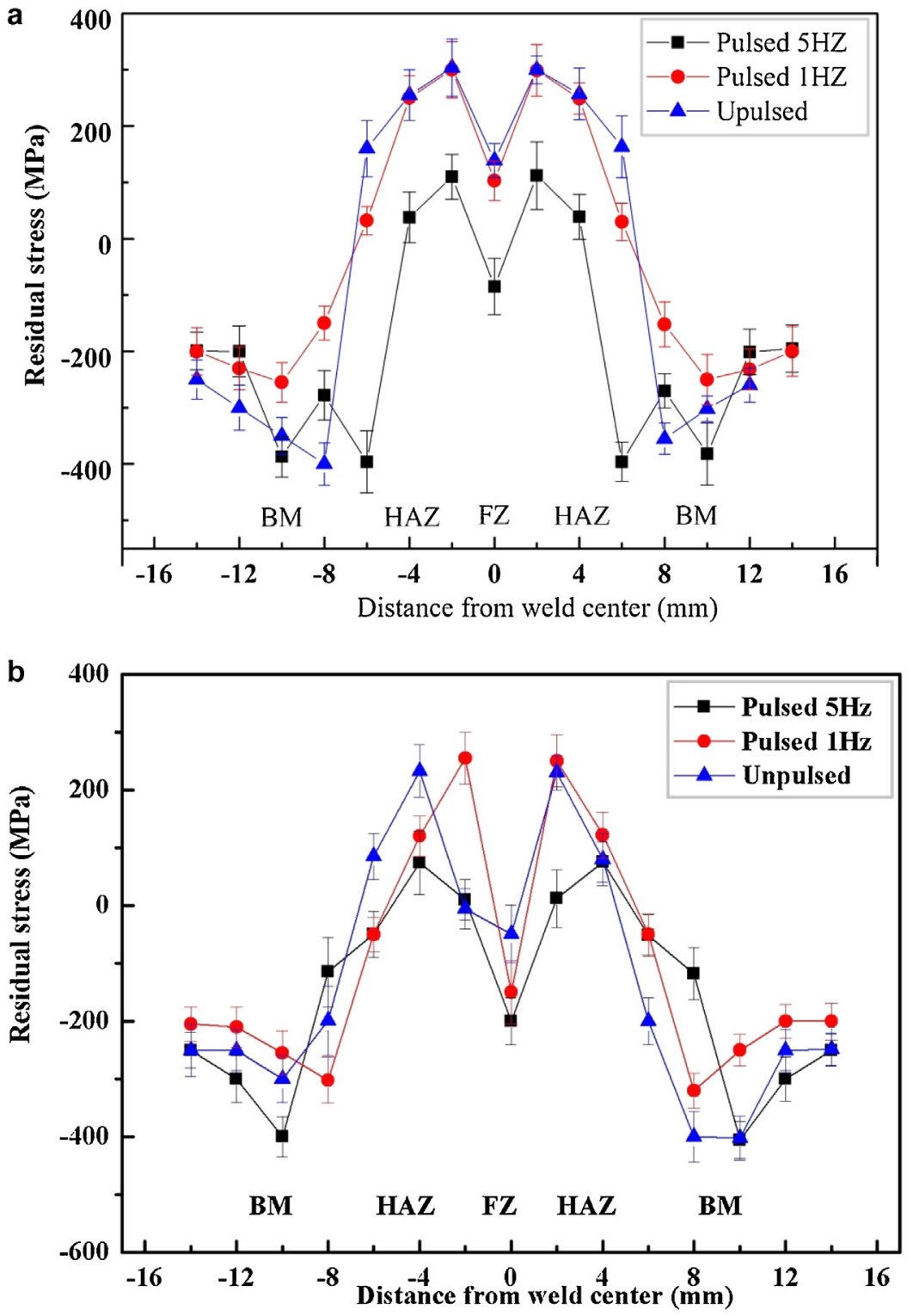

Fig. 8. Residual stresses distribution (a) longitudinal stresses (b) transversal stresses.

are generated. In addition, the RSs distributions in welds are the result of a complex combination of heterogeneous thermal strains due to thermal gradients induced by the welding process and volume changes induced by phase transformations. Moreover, the FZ and the HAZ are generally subjected to longitudinal and transversal tension RSs as simulated by Longuet et al. (2009) and explained by Casavola et al. (2012). In the case of the Ti-6Al-4V alloy, the transformation of the $\beta$ phase during cooling causes an increase in volume. So, the positive strains that are generated can reduce the tensile RSs, or in some cases induces compressive stress states as demonstrated by Appolaire et al. (2015). The influence of the plastic anisotropy can also explain the presence of these compressive stresses. Actually, the elastic anisotropy is very weak for titanium based alloys whilst the plastic anisotropy is very strong enough to cause high intergranular strains that can influence the stress level in the different studied zones.

Fig. 9(a,b) shows the average width of the diffraction peak $\{21-33\}$ used for RSs determination. The diffraction peak is in direct relationship with both the work-hardening and the quantity of crystalline defects in materials as reported by Ji et al. (1990).
It is observed that the peak width increases with the increase of the pulse frequency. This can be attributed to the inhomogeneous structures, formed after the welding process, which generate microscopic internal stresses at different scales and cause the plastic incompatibility during this process.

\section{Discussion}

As described above, complex microstructures, heterogeneous hardness and RSs are generated in the as welded Ti-6Al-4V sheets. In TIG welding process, the solidification occurs epitaxially through the formation of large prior- $\beta$ grains from the interface between the liquid FZ and the solid HAZ. According to Kishore and Ganesh (2006), a refinement of the prior- $\beta$ grains in the FZ is caused by a pulsed welding process and is related to the heat transfer and the fluid flow phenomena that occur in the weld pool. In our study, the grain refinement increases with the pulse frequency. The size of the prior- $\beta$ grains formed during the solidification of the weld pool is mainly governed by the solidification rate. This rate increases with the welding speed in the unpulsed process. However, in the pulsed 

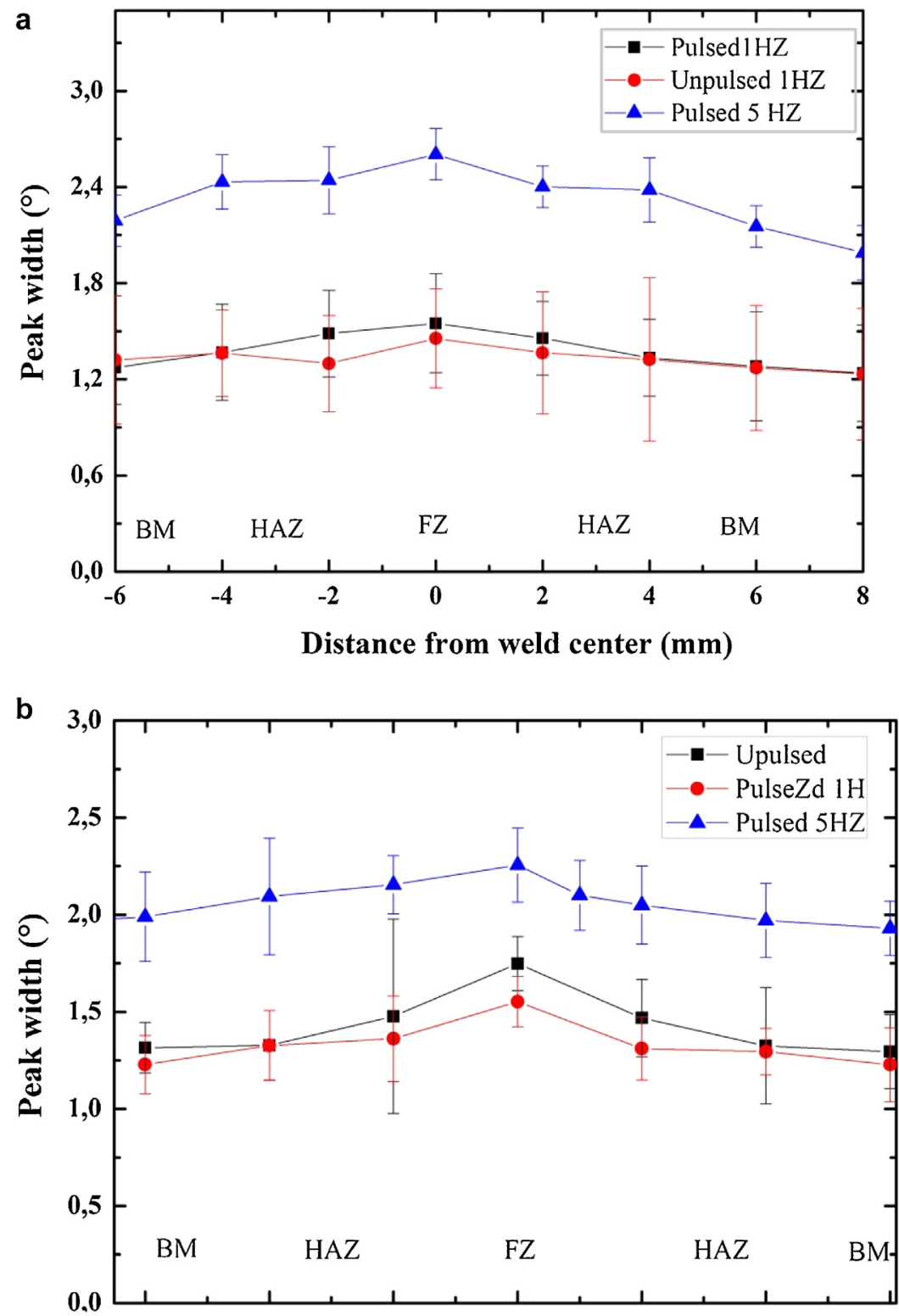

Fig. 9. Evolution of peak width used for residual stress determination, (a) longitudinal, (b) transversal.

process, the solidification rate is discontinuous, higher than the one in the unpulsed process, and increases with the pulse frequency.

According to Shi and Wang (2013), the microstructural development in the FZ is related to the variant selection phenomenon (different orientations of $\alpha$ and $\alpha$ lamellae with respect to the prior$\beta$ grain) that occurs under local stress during the $\beta \rightarrow \alpha$ transformation. In addition, the concentration of alloying elements such as $\mathrm{Al}$ and $\mathrm{V}$ within the matrix would have an effect on the transformation sequence of the $\beta$ phase as noticed by Gil et al. (2001). The volume fraction, the width and the morphology of $\alpha_{\mathrm{GB}}$ observed above, depend on the alloy chemistry, prior $\beta$ grain size and cooling rate. Kishore et al. (2007) and Gao et al. (2013) reported that the diffusional transformation of the $\beta$ phase in Ti-6Al-4V welds can take place to form either $\alpha$ phase or a mixture of $\alpha$ and $\alpha$. The formation of wide $\alpha$ laths in Ti-6Al-4V pulsed TIG welds was reported by Sundaresan et al. (1999) and Kishore and Ganesh (2006) who attributed it to the reduction of the cooling rate caused by the pulsed current and arc oscillation. According to Gil et al. (2001), the stability of the $\beta_{\mathrm{r}}$ phase observed in the pulsed process is ensured by the stabilizing elements that concentrate near the $\alpha_{\mathrm{GB}}$ phase during the phase transformation. In our case, the formation of $\alpha_{\mathrm{GB}}$ phase in the pulsed process and $\beta_{\mathrm{r}}$ phase in $5 \mathrm{~Hz}$ pulsed one can be attributed to the decrease of the cooling rate in the pulsed process after the rapid solidification in prior- $\beta$ grains. The pulsed current creates a "reheating" of the just solidified grains that decreases their cooling rate.

The RSs found in the several welding conditions studied in this work can be directly related to the pulse frequency, the degree of grain refinement of the prior- $\beta$ grains and the volume fraction of the different phases present across the weld joint. The RSs distribution is rather similar for the unpulsed and the pulsed welding at $1 \mathrm{~Hz}$. Conversely, RSs are significantly lower for the pulsed welding at $5 \mathrm{~Hz}$ with a change, compared to the other welds, from tensile to compressive stresses for the longitudinal stresses in the FZ. Guo et al. (2003) reported that the RSs increase with the volume fraction of the lamellar grains. This increase was on the one hand due to the deformation incompatibility across the lamellar interfaces and grain boundaries, and on the other hand, related to the localized stress field which becomes greater when the microstructure is more heterogeneous. The RSs in the weld joints develop mainly as 
a result of the typical nature of the welding process. During welding, several phase transformations occur in the HAZ and FZ of the Ti-6Al-4V alloy. These transformations are accompanied with an increase in specific volume at a microscopic level. Since the $\beta \rightarrow \dot{\alpha}$ transformation takes place at high temperature, its significant contribution to the development of compressive stresses can be expected. However, the cooling down to room temperature modifies the stress field due to thermal contraction. Depending upon the location and the temperature of this phase transformation, RSs may be either tensile or compressive in the FZ. Hessamoddin and Iradj (2014) attributed the change in the stress distribution pattern across the weld joint to the non-uniform expansion caused by the local heating, generated by the weld thermal cycles. Nitschke-pagel and wohlfahrt (2002) reported that, the initial state of the alloy, its chemical composition, the cooling conditions and the welding parameters would be the main factors that influence the volume expansion related to solid state transformations that occur during welding, which lead to the generation of compressive RSs. Previously, the formation of large proportions of $\alpha_{\mathrm{GB}}$ and $\beta_{\mathrm{r}}$ diffusional phases in the case of $5 \mathrm{~Hz}$ pulsed current welds was attributed to a lower cooling rate of the solidified weld pool. It can be deduced that this lower cooling rate is accompanied by a reduction in the magnitude of tensile residual stresses generated by the thermal effect in the FZ and HAZ. Thus, the volume change accompanying the phase transformations in the FZ favors the formation of compressive residual stresses which are beneficial to enhance static and fatigue performances of the Ti-6Al-4V welds.

\section{Conclusion}

TIG welding of the Ti-6Al-4V alloy induced complex microstructural transformations of its initial $(\alpha+\beta)$ microstructure to $\alpha, \alpha_{\mathrm{GB}}$ and $\beta_{\mathrm{r}}$ phases. Increasing the pulse frequency from 1 to $5 \mathrm{HZ}$ favored the grain refinement of prior $\beta$ phase in the FZ and the presence of more retained $\beta$ phase within its microstructure leading to a decrease of the microhardness.

The thermal strains, fluid flow phenomena as well as the volume expansion related to solid state transformations induced by the welding process were the main factors that influence the type of the residual stresses. The increase of the pulse frequency from $1 \mathrm{HZ}$ to $5 \mathrm{HZ}$ reduced the magnitude of the tensile residual stresses in the HAZ and weakened the compressive ones in the FZ.

\section{Acknowledgments}

The financial supports of the Research Centre in Industrial Technologies CRTI and ICMMO/SP2 M, Université-Paris-Sud are greatly acknowledged. The participation of the Mechanical and Civil Engineering Laboratory-(LMGC) Université de Montpellier II, France in this research work is also greatly acknowledged.

\section{References}

Ahmed, T., Rack, H.J., 1998. Phase transformations during cooling in $\alpha+\beta$ titanium alloys. Mater. Sci. Eng. A 243, 206-211.

Appolaire, B., Settefrati, A., Aeby-Gautier, E., 2015. Stress and strain fields associated with the formation of $\alpha$ in near- $\beta$ titanium alloys. Mater. Today: Proc. 2-3, S589-S592.
Balachandar, K., Subramanya Sarma, V., PANTB, Phanikuma, G., 2009. Microstructure and mechanical properties of gas-tungsten-Arc-welded Ti-15-3 beta titanium Alloy. Metall. Mater. Trans. A 40A, 2685-2693.

Balasubramanian, M., Jayabalan, V., Balasubramanian, V., 2008a. Developing mathematical models to predict tensile properties of pulsed current gas tungsten arc welded Ti-6Al-4V alloy. Mater. Des. 29, 92-97.

Balasubramanian, V., Ravisankar, V., Reddy, G.M., 2008b. Effect of pulsed current welding on mechanical properties of high strength aluminum alloy. Int. J. Adv. Manuf. Technol. 36, 254-262.

Casavola, C., Pappalettere, C., Tattoli, F., Tursi, F., 2012. Residual stresses and fatigue behavior of hybrid butt welded joints. NT2F 12, 169-186.

Chen, S.J., Devletian, J.H., 1990. Microstructure and mechanical properties of electroslag welds in Ti-6Al-4V Alloy. Weld. J. 69, 319-325.

European, standard, 2009. Test Method for Residual Stress analysis by X-ray Diffraction. NF EN 15305, april 2009.

Gao, X.L., Zhang, L.J., Liu, J., Zhang, J.X., 2013. A comparative study of pulsed Nd:YAG laser welding and TIG welding of thin Ti6Al4V titanium alloy plate. Mater. Sci. Eng. A 559, 14-21.

Gaoyang, M., Yanhong, W., Xiaohong, Z., Chend, G., Fengyi, Y., 2014. A coupled thermal and metallurgical model for welding simulation of Ti-6Al-4V alloy. J. Mater. Process. Technol. 214, 2434-2443.

Gil, F.J., Ginebra, M.P., Manero, J.M., Planell, J.A., 2001. Formation of $\alpha$-Widmanstatten structure: effects of grain size and cooling rate on the Widmanstatten morphologies and on the mechanical properties in Ti6Al4V alloy. J. Alloys Compd. 329, 142-152.

Guo, F.A., Ji, V., Francois, M., Zhang, Y.G., 2003. X-ray elastic constant determination and microstresses of $\alpha_{2}$ phase of a two-phase TiAl-based intermetallic alloy. Mater. Sci. Eng. A 341, 182-188.

Hessamoddin, M., Iradj, S.F., 2014. Resistance spot welding and the effects of welding time and current on residual stresses. J. Mater. Process. Technol. 214, 2545-2552.

Ji, N., Lebrun, J.L., Sprauel, J.M., 1990. Analysis of broadened X-ray diffraction profiles: application to the characterization of carbon steel. Mater. Sci. Eng. A 127, 71-77.

Jia, M.T., Zhang, D.L., Gabbitas, B., Liang, J.M., Kong, C., 2015. A novel Ti-6Al-4V alloy microstructure with very high strength and good ductility. Scr. Mater. 107, $10-13$.

Kishore, B.N., Ganesh, S.R.S., 2006. Influence of current pulsing on microstructure and mechanical properties of Ti-6Al-4V TIG weldments. Sci. Technol. Weld. Join. 11, 442-447.

Kishore, B.N., Ganesh, S.R.S., Mythili, R., Saroja, S., 2007. Correlation of microstructure with mechanical properties of TIG weldments of Ti-6Al-4V made with and without current pulsing. Mater. Charact. 58, 581-587.

Longuet, A., Robert, Y., Aeby-Gautier, E., Appolaire, B., Mariage, J.F., Colin, C., Cailletaud, G., 2009. A multiphase mechanical model for Ti-6Al-4V: application to the modeling of laser assisted processing. Comput. Mater. Sci. 46-3. 761-766.

Nitschke-pagel, T., wohlfahrt, H., 2002. Residual stress in welded joins-sources and consequences. Mater. Sci. Forum. 404, 215-226.

Noyan, I.C., Cohen, J.B., 1987. Residual Stress Measurement by Diffraction and Interpretation. Springer-Verlag.

Oh, J., Nack, J.K., Lee, S., Lee, E.W., 2003. Correlation of fatigue proprieties and microstructure in investment cast Ti-6Al-4V welds. Mater. Sci. Eng. A 340, 232-242.

Pasang, T., Sanchez-Amaya, J.M., Tao, Y., Amaya-Vazquez, M.R., Botana, F.J., Sabol, J.C., Misiolek, W.Z., Kamiya, O., 2013. Comparison of Ti-5Al-5V-5Mo-3Cr welds performed by laser beam, electron beam and gas tungsten arc welding. Procidia Eng. 63, 397-404

Shi, R., Wang, Y., 2013. Variant selection during a precipitation in Ti-6Al-4V under the influence of local stress-a simulation study. Acta Mater. 61, 6006-6024.

Sprauel, J.M., Rodriguez, R., Lebrun, J.L., Maeder, G., 1980. Contraintes résiduelles après soudage par procédé inerte gas et par faisceau délectrons de tôles épaisses en TA6V. J. Lea-Cordon Metals 69, 107-120.

Sundaresan, S., Janaki, R.G., Madhusudhan, R.G., 1999. Microstructural refinement of weld fusion zones in alpha-beta titanium alloy using pulsed current welding. Mater. Sci. Eng. A 262, 88-100.

Wang, S., Wu, X., 2012. Investigation on the microstructure and mechanical properties of Ti-Al-4Valloy joints with electron beam welding. Mater. Des. 36, 663-670.

Yang, Z., Qi, B., Cong, B., Liu, F., Yang, M., 2015. Microstructure, tensile properties of Ti-6Al-4V by ultra high pulse frequency GTAW with low duty. J. Mater. Process. Technol. 216, 37-47.

Zhang, J.X., Xue, Y., Gong, S.L., 2005. Residual welding stresses in laser beam and tungsten inert gas weldments of titanium alloy. Sci. Technol. Weld. Join. 10, 643-646. 